\title{
EI territorio vascón y sus ciudades en la era de Augusto
}

\author{
Javier ANDREU PINTADO \\ Universidad de Navarra \\ jandreup@unav.es
}

\section{RESUMEN}

El presente artículo ofrece un recorrido histórico sobre la información que, las fuentes literarias pero, fundamentalmente, las epigráficas y arqueológicas, nos ofrecen respecto del territorio atribuido por los textos clásicos a los Vascones antiguos en el marco cronológico del cambio de Era en general y de la época de Augusto en particular. Se estudian aspectos relacionados con el inicio del proceso de urbanización y vertebración territorial de la zona así como otros vinculados a la integración jurídica de las comunidades que lo integraron.

Palabras clave: Vascones. Urbanización. Augusto. Monumentalización urbana. Organización territorial. Colonización. Municipalización.

\section{The Territory of the Vascones and its Cities in Augustan times}

\begin{abstract}
The following paper offers an historical approach to the information that, coming from the literary sources but, mainly, from the epigraphic and archaeological ones, we have about the territory attributed to the ancient Vascones in the chronological period of the change of Era in general and in Augustus' time in particular. Aspects linked with the urbanization and organization of this territory and some of them connected with the juridical integration of its communities are also considered.
\end{abstract}

Key Words: Vascones. Urbanization. Augustus. Urban monumentalization. Territorial organization. Colonization. Municipalization. 
En el último decenio, la dedicación investigadora a los antiguos Vascones se ha incrementado notablemente ${ }^{1}$ en el marco, además, de un creciente interés por la cuestión de las etnias, las identidades y las implicaciones territoriales y administrativas de ambas realidades en el ámbito hispano. ${ }^{2}$ Sin embargo -en parte, sin duda, por el carácter tan sumamente elusivo de las propias etnias, ${ }^{3} \mathrm{y}$ en particular de la denominada "vascona", pero, también, por las limitaciones inherentes a las fuentes antiguas disponibles sobre aquéllas- las aproximaciones realizadas hasta la fecha sobre los Vascones antiguos han sido, habitualmente, de carácter sincrónico o general -aunque algunas cuestiones también han sido estudiadas desde una óptica más diacrónica- ${ }^{4}$ y prácticamente sólo para la Antigüedad Tardía -en la que el repertorio de fuentes sobre esta etnia histórica parece multiplicarse ${ }^{5}$ se han compuesto aproximaciones más acotadas cronológicamente. La revitalización de los estudios sobre Augusto que supone la celebración del bimilenario de su fallecimiento nos parecía que ofrecía una extraordinaria oportunidad para repensar algunas cuestiones sobre el territorio vascón de la Antigüedad Clásica $-\mathrm{y}$, en particular, sobre las ciudades que lo integraron ${ }^{6}$ y las infraestructuras que pusieron éstas en relación, asunto éste sobre el que hay algunas novedades reseñables-contribuyendo, también, a que las peculiaridades de los ámbitos locales resaltasen en nuestra comprensión de la Hispania de Augusto de un modo que, hasta ahora, no se había logrado ${ }^{7}$ atendiendo, además, a un momento que resultó también esencial en el espacio que nos ocupa, importancia que, sin embargo, tal vez hasta ahora, no se había subrayado del modo deseable,${ }^{8}$ carencia ésta que pretendemos suplir con las líneas que siguen.

Y lo cierto es que pocas cuestiones resultan tan oportunas y adecuadas como la relación entre este apasionante ethnos ${ }^{9}$ de la Hispania Antigua, los Vascones, y el periodo augusteo. No tanto por todas las razones que se esgrimirán en estas páginas como vía para caracterizar qué sabemos sobre la zona entre los años 31 a.C. y 14 d.C., sino, y de modo metodológicamente clave, porque tres de los autores que nos aportan información $-\mathrm{y}$, en gran medida, la más generosa, aunque siempre limitada- sobre

1 Sirvan, en este sentido, como testimonio, los trabajos incluidos en ANDrEu (ed.) 2006, 2009 y, el reciente ANDREU (ed.) 2013 además de otros trabajos que se citarán oportunamente a propósito de las distintas cuestiones aquí tratadas. Esta revitalización de los estudios sobre Vascones mereció, de hecho, no hace mucho, una completa valoración a cargo de uno de los pioneros en el estudio sobre la cuestión desde finales de los años sesenta: BlÁzQuez MARTínez 2007-2008.

2 Véase, por ejemplo, como hito más reciente respecto de la cuestión el volumen de SANTOS YANGUAS CRUZ ANDREOTTI 2013.

3 RoldÁn - WulfF 2001, 363-376.

4 Véanse, por ejemplo, los trabajos de Andreu 2004-2005, o el de RAmíRez SÁDABa 2006.

5 Con la bibliografía previa, en parte incluida en los volúmenes citados en la nota 1, puede verse TORREGARAY 2013 o NAVARro 2010.

6 Commoditatis causa, de nuevo, las ciudades catalogadas, en alguna ocasión, como vasconas, en las fuentes antiguas, volverán a ser el eje de las que se valorarán en las próximas páginas, siguiendo el inexcusable y todavía extraordinario catálogo de Peréx 1984, 71-232.

7 Como ejemplo del carácter general de esa aproximación, puede verse el clásico trabajo de RoDRíGUEZ Colmenero 1979.

8 Anótese, como excepción, la aproximación detallada realizada por LARRAÑAGA 2007, 84-92, con su capítulo "La obra reorganizadora de Augusto: su reflejo en el área".

9 Str., 3.4.10. 
el asunto, escribieron en la época a la que se consagra este volumen -como Livio o Estrabón- o bien -como Plinio el Viejo- manejando información fechada en aquél tiempo, y todos forman parte, además, de la ideología historiográfica y enciclopédi$\mathrm{ca}^{10}$ que siguió a la proclamación por parte de Octaviano de su novus status. ${ }^{11}$

Efectivamente, y como se ha subrayado recientemente para el caso de Plinio ${ }^{12}$ y se hizo ya hace algún tiempo para el de Estrabón, ${ }^{13}$ prácticamente, ninguna de las menciones que estos dos autores hacen en relación a los Vascones resulta baladí o anecdótica y todas ellas están presididas por los propósitos a los que-especialmente Estrabón y Plinio pues el caso de Livio, que, además, apenas nos habla de un conocido episodio de las guerras sertorianas (76 a.C.) acaecido en torno a Calagurris e in confinio Beronum, ${ }^{14}$ presenta los habituales problemas historiográficos que acompañan a la narración de episodios bélicos por parte de este autor ${ }^{15}$ aquéllos sirven desde una óptica política y cultural. ${ }^{16}$ Efectivamente, a Estrabón le debemos la noticia de la relación de los Vascones con el Pirineo ${ }^{17}$-muy de su gusto de geógrafo, siempre orientado a ensalzar la relación entre los grupos humanos y el espacio que ocupan, ${ }^{18}$ que acababa por condicionar su bios, su modo de vida- ${ }^{19}$ pero, también, la consignación de que en ese agreste territorio existen elementos materiales de romanidad concretados en la presencia de vías de comunicación -en concreto la que unía Tarraco y Oiasso- ${ }^{20}$ y, también, de ciudades -Calagurris, Pompelo y Oiasso- ${ }^{21} \operatorname{los}$ dos agentes de civilización que el contacto con Roma generaba en las otrora incógnitas tierras y que estimulaba, de hecho, su transformación cultural ${ }^{22}$ y la conversión de sus gentes en politikoi. ${ }^{23}$ Por su parte, Plinio -habitualmente invocado para el estudio de las ciudades vasconas a partir de su célebre descripción de los populi del conventus de Caesar Augusta ${ }^{24}$ puesta en relación con la que Ptolomeo ofrece como póleis de dicha etnia- ${ }^{25}$ entronca con la tradición estraboniana de gusto geográfico pero añade a ella una dimensión claramente administrativa ${ }^{26}$ aportando información que consideraba fundamental o, mejor dicho, que consideraron ya fundamental Agripa y Au-

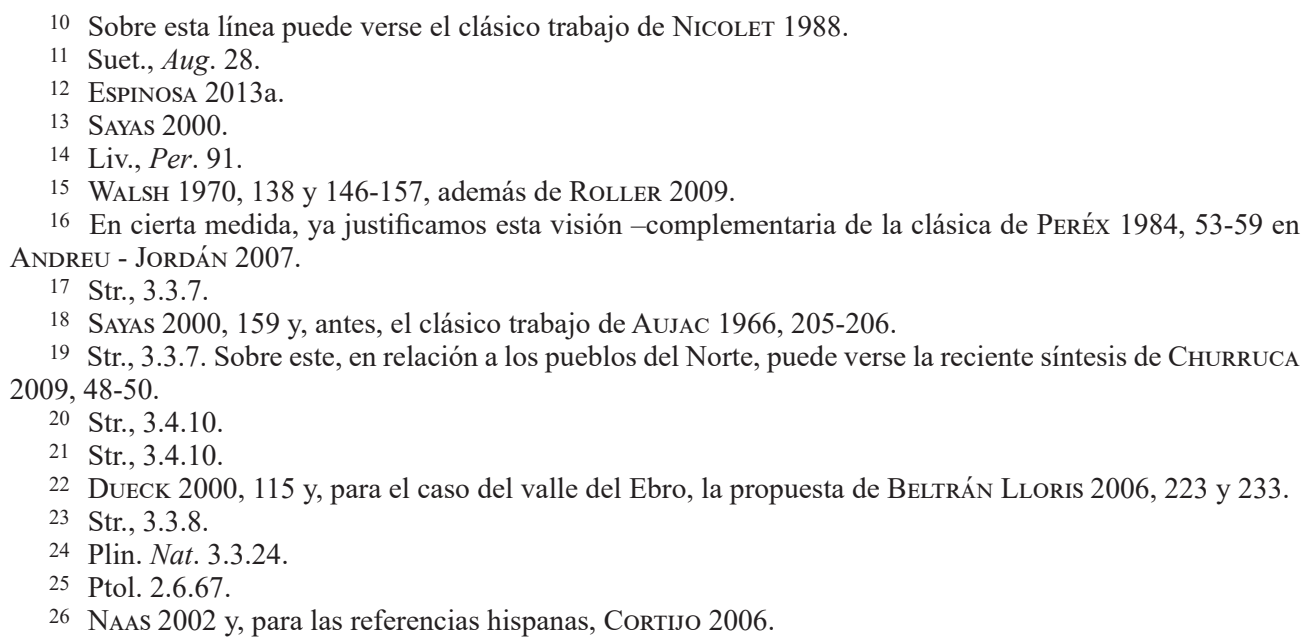

16 En cierta medida, ya justificamos esta visión -complementaria de la clásica de PERÉx 1984, 53-59 en ANDREU - JORDÁN 2007.

17 Str., 3.3.7.

18 SAYAS 2000, 159 y, antes, el clásico trabajo de AuJAC 1966, 205-206.

19 Str., 3.3.7. Sobre este, en relación a los pueblos del Norte, puede verse la reciente síntesis de CHURRUCA

20 Str., 3.4.10.

21 Str., 3.4.10.

22 Dueck 2000, 115 y, para el caso del valle del Ebro, la propuesta de Beltrán Lloris 2006, 223 y 233.

23 Str., 3.3.8.

24 Plin. Nat. 3.3.24.

25 Ptol. 2.6.67.

26 NAAs 2002 y, para las referencias hispanas, CORTIJO 2006. 2009, 48-50. 
gusto, especialmente, en su dimensión económica, práctica, ${ }^{27}$ y política, dos ideales de referencia, también, en la metodología pliniana ${ }^{28}$ Precisamente eso explicaría la atención del de Como al Pirineo como frontera de separación entre Galia e Hispania ${ }^{29}$ -una percepción administrativa posterior exclusivamente a la conquista y a la reorganización territorial y administrativa del septentrión hispano- ${ }^{30} \mathrm{o}$ al controvertido, ${ }^{31}$ y recientemente esclarecido, tema del Vasconum saltus. ${ }^{32}$ Es pues evidente que tanto Estrabón como Plinio destacaron -en lo relativo a la caracterización del denominado solar vascón- elementos muy del gusto augusteo, lo hicieron, además, con carácter enciclopédico y, seguramente, por la importancia simbólica - para el caso de Estrabón- pero también económica y administrativa -para el caso de los datos aportados por Plinio- de los elementos anotados que, no en vano -en particular la vía TarracoOiasso y también el carácter minero del Vasconum saltus- consta que comenzaron a ser importantes económicamente con el comienzo del Principado ${ }^{33}$ y cuyo conocimiento interesaba salvaguardar $y$, adecuadamente, a partir de entonces, gestionar. ${ }^{34}$ Además, muy probablemente, la diversidad lingüística ${ }^{35}$-pero también de carácter cultural y de grado de integración- ${ }^{36}$ que ofrecía el solar de los Vascones hicieron que su estudio, en el marco de la descripción sobre los espacios que habían sido escenario de la conquista de la Península Ibérica, resultase sugerente y, en cierta medida, ejemplificador de la capacidad romana de crear una oikouméne sobre un sustrato bien diverso.

Pero, más allá de las cuestiones heurísticas - que, por otra parte, no debe olvidarse que son las que nos permiten caracterizar mejor el que fuera el espacio atribuido por las fuentes antiguas a los Vascones ${ }^{-37}$ ahora que, gracias a un mejor escrutinio de las fuentes literarias y a nuevos hallazgos epigráficos, conocemos mejor los motivos y circunstancias de la presencia de Augusto en la Península Ibérica ${ }^{38}$ puede concluirse que, muy probablemente, los tres viajes del Princeps a nuestro solar-el desarrollado en el 45 a.C., el que tuvo lugar, con paso más que seguro por el valle del Ebro, entre el 27 y el 24 a.C., con motivo de las guerras cántabras, y, por último, el del 16/13 a.C. en el que se inscribió la fundación de Caesar Augusta- tuvieron relación, de uno u otro modo - o, cuando menos, incidencia- con el solar de los Vascones y, por supues-

27 DuecK 2010, 125.

28 ESPINOSA 2013a, 674-677 y, también BRACESSI 1982.

29 Plin. Nat. 4.20.110.

30 BeLtrán LloRis - Pina 1994.

31 Santos Yanguas 2007-2008, además de la revisión que, desde una óptica más sociológica, hemos desarrollado en ANDREU 2013, 364-365.

32 Plin. Nat. 4.20.110. Para la propuesta de identificación del saltus pliniano con el entorno minero de Oiasso, debe verse UrTEAGa 2007-2008, 177.

33 Con carácter general y bibliografía véase LARRAÑAGA 2007, 85-87, asuntos, en cualquier caso, sobre los que volveremos pronto.

34 EsPinOsa 2013a, 674.

35 Veánse, además del clásico trabajo de Gorrochategur 2009, los apuntes que, respecto de la toponimia del solar vascón, realiza GARCía Alonso 2003, 467-470.

36 ANDREU - JoRdán 2007, 241 además de, para el caso estraboniano, SAYAS 2000, 168 y 177.

37 Para la delimitación de dicho solar nos sigue pareciendo de referencia el trabajo de CANTÓN 2005, 142.

38 Abascal 2006. 
to, también con el Ebro Medio, contexto geográfico que no debe perderse de vista al analizar los avatares de la región que nos ocupa. Así, hace algunos años, y a propósito de la manus Calagurritanorum con que, a decir de Suetonio, ${ }^{39}$ contó Octaviano y que nos consta que aquél licenciaría con posterioridad a Actium, se planteó ${ }^{40}$ que aquél hubiera conocido a algunos de esos efectivos - sin duda, de fama ligada a la ferocitas de la conocida fames Calagurritana ${ }^{41}$ entre la guardia hispana que también sabemos que acompañaba, por millares, a César. ${ }^{42}$ Además, recientemente, se ha supuesto que, en el viaje augusteo del 26 a.C., en que el Princeps acudió a ocuparse directamente de las guerras cántabras y hubo, por tanto, de atravesar el valle del Ebro con dirección a la Meseta y a la costa del Cantábrico -siguiendo una ruta que, después, él mismo se ocuparía de monumentalizar, la denominada vía de Italia in Hispanias-, ${ }^{43}$ el débil Augusto debió tomar las aguas en Turiaso para, de ese modo, combatir la afección hepática que, sabemos, padecía. ${ }^{44}$ Tal vez en dicho contexto, como veremos más adelante, debieron promocionar las comunidades, calificadas como populi Latinorum veterum o como populi civium Romanorum del poco después constituido como distrito de Caesar Augusta, a saber, para el territorio que nos ocupa, Calagurris, Graccurris y Cascantum $^{45}$ que, pronto, encontraremos acuñando moneda ${ }^{46}$ y sobre cuyo cambio estatutario volveremos más adelante. Por último, y como dijimos, en torno al año 15 a.C. se produjo, finalmente, en el centro del valle del Ebro, y tras el licenciamiento de los veteranos de las guerras cántabras, la deductio de la colonia Caesar Augusta, un acontecimiento central en la historia del Ebro Medio -auténtico colofón a la política previa de romanización en la zona- ${ }^{47}$ y que, como no podía ser de otro modo, las fuentes epigráficas y, también, arqueológicas, están demostrando que resultó también capital para muchas de las ciudades de los Vascones, en especial las instaladas en el área más septentrional y oriental de su territorio.

Efectivamente, el análisis de la organización territorial del Ebro Medio a partir de la fundación de Caesar Augusta pone claramente de manifiesto -y así se ha subrayado con notable frecuencia- ${ }^{48}$ que la colonia exigió una reorganización notable de la red viaria actuando aquélla como auténtico nudo de comunicaciones y, en particular, de una red de comunicaciones orientada a garantizar la seguridad y la vertebración

39 Suet., Aug. 41.1.

40 Espinosa 1984, 72-74.

41 Sobre esa relación, véase JoRDÁn 2006, 113-114.

42 Cic., Att. 13.52.1.

43 ArIÑo ET ALII 1997.

44 Suet., Aug. 59.81 y Cass. Dio, 53.30.3. Beltrán Lloris 2002. Sobre el contexto véase también BeltráN Lloris - MARTín-BuenO - Pina 2000, 73-76.

45 Abascal 2006, 76 además de la información que, respecto de las tres comunidades, recogimos en ANDREU 2006, 187-192.

46 García y Bellido - Blázquez 2001, 222-225, 155 y 219 para Calagurris, Gracchurris y Cascantum respectivamente.

47 Roddaz 1986, 338 y, por extenso, BELTRÁn Lloris 1992.

48 Magallón 1987, 58, además de, antes, Dupré 1973, 171. En relación con esa fecha como clave para la reordenación territorial del Norte peninsular y, en particular, del piedemonte pirenaico, debe verse BosT 2009,115 . Sobre las ciudades que hacen de nudo viario como predilectas de la administración y el urbanismo augusteo en las Hispanias sigue siendo válido BENDALA 1990. 
del interior del valle. Como probaron, además, a comienzos de los años ochenta, algunos miliarios (ERZ 11 y 19 e IRMN 1), ${ }^{49}$ parece que los veteranos de la legio IIII Macedonica, la VI Victrix y la $X$ Gemina, con quienes Augusto, in persona, había fundado la ciudad, se ocuparon, entre los años 9 y 4 a.C. ${ }^{50}$ del trazado de una vía que, seguramente -como se ha demostrado recientemente- modificaría el trazado de una antigua que, tal vez, pudo haber sido empleada en época de las guerras sertorianas e, incluso, con anterioridad, ${ }^{51}$ coincidente, a nuestro juicio, en el ramal denominado "de las Cinco Villas", ${ }^{52}$ con la Tarraco-Oiasso descrita por Estrabón y a la que ya antes aludimos. Estos documentos epigráficos han sido, además, en los últimos años, puestos en relación con otros que, en el contexto de la fundación de Barcino, atestiguan la colaboración de vexillationes legionarias en la construcción de importantes obras de infraestructura -como el Pont del Diable de Martorell- ${ }^{53}$ o con los que -aparecidos en el puerto fluvial de Caesar Augusta ${ }^{54}$ y en la presa de Muel, en las proximidades de Zaragoza ${ }^{55}$ remiten a un acontecimiento de idéntica naturaleza para el entorno de la colonia Caesar Augusta. A este repertorio, precisamente, se ha unido en los últimos años un singular conjunto de evidencias epigráficas procedente de la ciudad romana de Los Bañales de Uncastillo, en el sector nororiental del solar de los antiguos Vascones, acaso la Tarraca citada por Plinio ${ }^{56}$ como populus foederatus y referida también por el cosmógrafo de Rávena en la ruta entre Caesar Augusta y Pompelo a la que venimos aludiendo. ${ }^{57}$

Efectivamente, una serie de veinte marcas inscritas sobre los sillares de Los Pilarones del acueducto de la ciudad, marcas que parecen remitir a la legio III Macedonica ${ }^{58}$ documentarían que una vexillatio de dicho cuerpo legionario -que, nos consta, como vimos, estuvo trabajando por la zona en la apertura del nuevo ramal de la vía que unía Caesar Augusta con Pompelo- se ocupó de construir esa obra hidráulica con una solución -de caneles lignei- que, no demasiado atestiguada en las fuentes clásicas, ${ }^{59}$ convenía, sin embargo, muy bien a una obra de carácter militar. No en vano la documentación epigráfica evidencia, en otros rincones del Imperio, de qué modo las unidades legionarias tenían capacidad y personal suficiente para llevar a cabo este tipo de obras ${ }^{60}$ empleando sus cuadrillas de operarios especializados para evidenciar

49 Para la presentación de uno de ellos, y el debate histórico, paralelo a todos, véase CASTILLO 1981 y, fundamentalmente, el estudio de Gómez-PANTOJa 2000, 109, n. 21.

50 Lostal 1992, 269.

51 AMELA 2000-2001.

52 Aguarod - Lostal 1982 y Magallón 1987, 142. Sobre la misma puede verse, además de Rav. 4.4344, lo que anotan sobre ella SAYAS - PerÉx 1987, 589.

53 GURT - RODÀ 2005.

54 Beltrán LloRis 2007-2008.

55 Uribe ET ALII 2011, 343. Podría tratarse de una marca de la Legio VI la atestiguada en un sillar de la presa de El Sotillo, en Gracchurris (Alfaro) (HEp 9, 482) conforme a HernáNDEZ Vera - MarTínez TORRECILLA - NúÑEZ 1999.

56 PERÉX 1988.

57 Plin. Nat. 3.24; Ptol., 2.6.67 y Rav., 4.43-44.

58 JORDÁN 2011, 326-330, nº 77-86.

59 Véase, sobre su utilidad y su frecuencia como solución estructural, en época romana: Cet. Fav. 6 y 12.

60 CIL VIII, 2728 de Lambaesis, en Numidia, estudiada en detalle por LAPORTE 1996, 736-754. Para los auxilios constructivos prestados por las unidades legionarias que, nos consta, colaboraron en la denominada 
de qué modo, como afirma Casio Dión, el Princeps al que servían, había puesto el ejército a disposición del bien del Estado. ${ }^{61}$ Una colaboración de estas características, a nuestro juicio, está plenamente justificada desde el punto de vista histórico -no en vano, nos consta la participación del ejército en la obra viaria de la zona que debió tener un carácter especialmente estratégico, como después veremos- y tampoco creemos que el carácter no privilegiado de la ciudad que hubo en Los Bañales suponga un obstáculo para que aquélla se materializara, máxime si tenemos en cuenta que en este caso se trataba de colaborar con la integración y vertebración de una civitas que constituía un punto importante en esa nueva $-\mathrm{y}$ nítidamente estratégica $-{ }^{62}$ calzada y que, además, podría, incluso, tratarse de una ciudad de estatuto jurídico federado.

Más aun, y aunque todavía no tengamos fuentes para certificarlo, no resultaría aventurado pensar que -como sucede en otros ámbitos peninsulares ${ }^{63}$ ese tipo de trabajos obligaron a los veterani de estos cuerpos legionarios a desplazarse desde Caesar Augusta y asentarse, al menos temporalmente, en las comunidades por las que pasase la vía en la que estaban trabajando y durante el tiempo en que se prolongasen esos trabajos. Eso implicaría, quizás, que Los Bañales -cuya plaza pública exhibe un primer horizonte monumentalizador coincidiendo con el cambio de Era y con la época augustea ${ }^{64}$ y dominando, precisamente, el enclave, el paso de la citada vía ${ }^{65}$ pudiera ser el enclave en que -a modo de statio militum $-{ }^{66}$ se produjo ese asentamiento por más que, al margen de la lógica histórica, no tengamos pruebas arqueológicas al respecto, todavía, sobre este extremo ${ }^{67}$ y que ello, con el consiguiente incremento poblacional, obligase a la civitas a contar con un nuevo aporte hídrico. Lo que sí es necesario subrayar es que, si se tienen en cuenta los parámetros en que se movió la actuación castrense en la época en la Península Ibérica, ${ }^{68}$ el interés de las legiones de Augusto en el área nororiental del solar de los Vascones tuvo que obedecer, muy probablemente, no sólo a razones de tipo estratégico - se trata, como se ha demostrado recientemente, de un camino natural de unión entre el Ebro Medio y el Pirineo Central ${ }^{69}$ y de una ruta que, por tanto, el propio Agripa, habría conocido en su viaje

\footnotetext{
"vía de las Cinco Villas" puede verse la exhaustiva documentación aportada por Gómez-Pantoja 2000a y, también, 2000b, 179, nota 77 .

61 Cass. Dio, 54, 27 y, a partir de él, Beltrán Lloris 2007-2008, 1073.

62 CASTIElla 2003, 273.

63 Suet., Aug. 32.1 o Tert., Apol. 2.8, comentados en detalle, para el caso hispano - con alusión a los casos de colaboración legionaria en torno a Barcino, Caesar Augusta y las Cinco Villas de Aragón- en Palao 2013, 96-97 y 101.

64 ANDREU ET ALII 2014.

65 Magallón 1990, 39-40.

66 Suet., Tib. 37.1-2.

67 Sí podría, en este sentido, tomarse en consideración el material vítreo de carácter militar que ha sido estudiado, en el registro arqueológico del enclave, por OrTIZ - PAZ 2011, 377-378. Para un caso de statio del ejército en el proceso de reforma y reorganización territorial de una civitas, puede verse el caso de Baetulo, descrito por ANTEQUERA ET ALII 2010, 176-180. En el territorio de los Vascones pudo cumplir una función semejante -aunque, seguramente, la instalación militar resultase más tardía, al menos ya de época tiberiana-el enclave de Iturissa, en Espinal, controlando uno de los pasos pirenaicos occidentales (PerÉX - UnzU 19971998, 118-121).

68 PaLAO 2013, 105.

69 Moreno 2009.
} 
por Aquitania- ${ }^{70}$ sino, muy probablemente, también, de tipo productivo y económico. Así, la madera y acaso el esparto ${ }^{71}$ y, por supuesto, el aceite, el cereal y el vino, pudieron constituir los motores del interés oficial en la zona, quizás en relación con la annona militaris y con la exportación de dicho excedente bien hacia el Cantábrico, por el puerto de Oiasso, bien hacia la Galia, por los pasos pirenaicos. ${ }^{72}$ Este interés en esos productos, además, encuentra su refrendo - cada vez mejor documentado- en otros datos que, para todo el ámbito vascónico y pirenaico, van evidenciando la puesta en explotación, precisamente a partir de época de Augusto, de todo tipo de recursos productivos en la zona, tales como la cantería del mármol de Saint-Béat, ${ }^{73}$ los trabajos en los metalla de Aiako Harria en el entorno de Oiasso, ${ }^{74}$ la explotación agrícola a través de la instalación del modelo de las villae ${ }^{75} \mathrm{o}$ la difusión de las cerámicas del taller gálico de Montans, cada vez mejor atestiguada en las ciudades romanas del ámbito nororiental del solar vascón ${ }^{76}$ por citar sólo algunas de las que, ahora, empezamos a conocer mejor. ${ }^{77}$

Lógicamente, y éste capítulo constituye uno de los hitos clave en la historia de la integración no sólo del Ebro Medio sino, también, del área nororiental del solar vascón, ${ }^{78}$ la presencia del ejército realizando trabajos de adecuación territorial e infraestructura -que, además, cada vez, para la época augustea, se revela como una praxis más general en la Península Ibérica- ${ }^{79}$ dejó una incidencia que excede, sin duda, los trabajos atestiguados y que motivaron su presencia en la zona. Así, por ejemplo, para este periodo -seguramente poco después del año 6 a.C.- consta que uno de los enclaves urbanos de las actuales Cinco Villas de Aragón -lamentablemente el contexto secundario del hallazgo nos impide saber cuál, acaso la que hubo en Los Bañales de Uncastillo- promovió una dedicatoria a Cayo César $(H E p ~ 5,916),{ }^{80}$ uno de los nietos del emperador Augusto, dedicatoria que debe inscribirse en el marco de la política de imagen dinástico desarrollada por el Princeps a partir del año 12 a.C. ${ }^{81}$ La presencia del ejército en la zona debió, sin duda, estimular la llegada al lugar de este tipo de homenajes que nos constan también, por ejemplo, en la capital del distrito, Caesar Augusta y que formaron parte de la propaganda oficial desarrollada por el nuevo régimen. Más aun, la apertura de esa vía de comunicación que enlazaba las

70 Str., 4.6.11.

71 Andreu 2011, 19-100.

72 PEÑa 2010, 161-166 y 168-169. Véase al respecto, con bibliografía, la propuesta de ZuZA 2013.

73 SCHENCK 1995.

74 Cauvet - Domergue - Urteaga 2005, 423-460.

75 MezQuíriz 1995-1996, 147.

76 Lasaosa 2013, 312-313 o, para el caso de Cara, MezQuíRIz 1977, 599. Para las primeras importaciones, en época augustea, en Andelo, sobre la que luego volveremos, debe verse MEZQUíriz 2009, 38-39.

77 Una panorámica general puede verse en LARRAÑAGA 2007, 85, además de en la síntesis de LARRAÑAGA 2009.

78 Beltrán Lloris - Martín-Bueno - Pina 2000, 75 y 82 además de Andreu 2011, 33-38.

79 Véase, por ejemplo, Salinas - Palao 2012.

80 Sobre las circunstancias del hallazgo, lamentablemente en contexto secundario, debe añadirse, a la bibliografía anotada por ANDreu 2011, 37, n. 74, LAMBÁn 1982 y, también, Beltrán LloRis 1992, que, de hecho, conecta el homenaje con la presencia militar en la zona entre los años 9 y 5 a.C.

81 Abascal 1996, 63 y 70. 
tierras del Ebro con el Cantábrico y con el Pirineo Occidental y, por tanto, con la Galia, debió cambiar notablemente la faz de algunas de las ciudades que fueron surcadas por dicho camino o de las que se encontraban próximas a él lo que evidencia de qué modo la vertebración territorial fue unida a la aceleración del proceso de integración en estos primeros siglos del Principado. Así, por ejemplo, nos consta que para época de Tiberio, la civitas de los Carenses (Santacara, Navarra), citada por Plinio el Viejo ${ }^{82}$ (CIL II, 4904 y 4905 además de ERZ 30, de Sádaba) no sólo había comenzado ya su proceso de monumentalización ${ }^{83}$ sino que, en poco tiempo -para la época de Tiberio-, habría visto construirse un ramal que, desde la vía principal -la levantada por las legiones, a la que estamos aludiendo-, la enlazaba con aquélla y con Pompelo siguiendo el curso del río Aragón. ${ }^{84} \mathrm{Si}$ esto sucedió en ciudades no directamente atravesadas por la nueva vía de carácter militar, resulta plausible pensar que otras, llamadas a cumplir un papel importante en la nueva organización del territorio, experimentasen en el cambio de Era una transformación notable, tal vez, incluso, reflejo de la verdadera instalación del modelo de la civitas en la zona. Acaso pudo ser eso lo que sucedió en el núcleo urbano, aun de nombre desconocido, de Campo Real/Fillera, en las proximidades de Sos del Rey Católico. La cronología del abandono de los poblados de la Edad del Hierro II circundantes, la fecha de algunos de los materiales recuperados en superficie en el lugar y, por supuesto, el aspecto extraordinariamente ortogonal que, en fotointerpretación de la fotografía aérea, ofrece su planta, permiten suponer con relativa verosimilitud que tal vez se trató de una civitas organizada casi ex novo, de nueva planta, ${ }^{85}$ para controlar un punto de auténtica encrucijada viaria entre los caminos que, desde la Canal de Berdún y por el río Irati permitían acceder al Pirineo pero, también, a la Cuenca de Pamplona. ${ }^{86}$

Ciertamente, no fue ésta la única obra de infraestuctura acometida en este momento en el territorio de los antiguos vascones. La propia via de Italia in Hispanias, que atravesaría las ciudades vasconas más meridionales -las de Cascantum, Calagurris y Gracchurris - consta que fue monumentalizada y reorganizada a partir de época de Augusto, a juzgar por los miliarios (HEp 6,790) y que, también, tuvo -en su penetración hacia la Meseta- a la ciudad de Caesar Augusta como eje. No en vano ésta aparece referida como caput viae en un miliario de Arancón (Soria), fechado hacia el año 9 a.C. (HEp 7, 940) ${ }^{87}$ Es muy posible que este interés oficial en esta vía de penetración hacia la Meseta guardase, lógicamente, relación con otro de los hitos clave de la política augustea y que, como arriba anticipamos, dejó también su huella en el solar

82 Plin., Nat. 3.3.24.

83 Mezquíriz 2006, 154-158.

84 Galve - Magallón - Navarro 2005, 199; Mezquíriz 2006, 148 y también Magallón 1987,151 además de CASTIELla 2003, 273.

85 ANDREU - JoRDÁN - ARMENDÁRIz 2010, 195 con la bibliografía sobre el enclave que, en los últimos años, ha aumentado notablemente.

86 Véase, al respecto, MoREno 2009, 94-95 y, también, sobre ese surgir, con bases arqueológicas, del modelo de las civitates en el área afectada por esta importante arteria de comunicación, el trabajo de ARMENDÁRIZ 2008, 305-308.

87 Sobre esta reorganización, y su incidencia en torno al municipium de Calagurris, puede verse el trabajo de Castillo Pascual 2002, esp. 13-14. Sobre ese carácter de nudo viario de Caesar Augusta en relación a la via de Italia in Hispanias puede verse ARIÑo ET ALII 1997, 246. 
vascón: la promoción jurídica de ciudades. ${ }^{88}$ Gracias a los datos aportados por Plinio, y a las acuñaciones monetales, sabemos que Calagurris, Cascantum y Gracchurris promocionaron al estatuto jurídico de municipios en época de Augusto, la primera al de municipio romano y las otras dos comunidades al de municipia Latina. Probablemente, y aunque existen todavía dudas sobre la fecha, la promoción de Calagurris pudo operarse poco después del 31 a.C., y conectarla con el licenciamiento de la $m a$ nus Calagurritanorum a que antes se aludió ${ }^{89}$ mientras que la de las comunidades de Cascantum y de Grachurris - para las que, recientemente, se ha propuesto un estatuto republicano de colonias latinas ${ }^{90}$ previo a su maduración municipal augustea- debió producirse en el marco del segundo de los viajes de Augusto a Hispania, momento en que, de hecho, el propio Princeps, en relación con su actividad en las guerras cántabras y con su paso por Turiaso -que también promocionó jurídicamente a municipio en este momento- ${ }^{91}$ debió pasar por el solar de los Vascones bien por algunas de sus civitates-Gracchurris o Cascantum si, conforme al Itinerario de Antonino, ${ }^{92}$ realizó ese viaje de regreso a Tarraco ${ }^{93}$ por el sector más septentrional de las comunicaciones con la Meseta, la ab Asturica Tarracone- bien, si prefirió realizarlo por Clunia ${ }^{94}$ sólo por el extremo más oriental del territorium del municipium Cascantum, extremos que, en cualquier caso, no pueden probarse. Sí resulta representativo, de todos modos, que para el caso de Gracchurris, la monumentalización de la red viaria y la promoción municipal motivasen -como veremos que sucedió en otras ciudades del solar que nos ocupa incluso en aquéllas para las que no consta una evolución jurídica en el marco del gobierno de Augusto- una intensa actividad de transformación urbanística en el interior del núcleo urbano -prácticamente arrasando todo el urbanismo romano republicano precedente $-{ }^{95}$ pero, también, otra de ornamentación de la propia vía con la construcción, a sus pies, de un templo y de un ninfeo que, muy probablemente, deba fecharse en época de Augusto. ${ }^{96}$ La situación de propugnacula de todas estas ciudades respecto del norte y el noroeste peninsulares ${ }^{97}$ y el área cantábrica además de, desde luego, sus posibilidades productivas $\mathrm{y}$, fundamentalmente, metalúrgicas, las habría hecho atractivas a la política augustea. A este respecto, puede traerse a colación el pocas veces aludido hallazgo de Monte Perdiguero (Calahorra), ${ }^{98}$ con-

88 Sobre ella véase Cass. Dio, 54.23.7, además de $R G 16.1$.

89 Sobre esta cuestión puede verse EsPINOSA 1984, 85-95 además de, recientemente, SAYAS 2010, 75-76. Para argumentos internos - de interdependencia de las élites de unas y otras de estas ciudades y, en particular, de las de Calagurris con las de Cascantum - puede verse nuestro trabajo ANDREU 2009, 120.

90 Espinosa 2013b, 110-120, para el caso de Gracchurris, también desarrollado, antes, por GARCíA FERNÁNDEZ 2009.

91 Para la promoción de esta comunidad y sus implicaciones, puede verse el reciente trabajo de AmELA 2012-2013, 96.

92 It. Ant. 448, 2. Para las diversas posibilidades, en la zona, fusión de los trayectos Ab Asturica Terracone, De Italia in Hispanias y Ab Asturica per Cantabria Caesaraugusta, debe verse Magallón 1987, 161.

93 Floro, 2.33 y Cass. Dio, 53.25.2.

94 Moreno 2001.

95 Todas esas transformaciones, con la bibliografía - aun insuficiente- al respecto son extraordinariamente bien descritas por ESPINOSA 2013b, 110-120.

96 Véase Hernández Vera - Martínez Torrecilla - NúÑEz 1997.

97 Beltrán Lloris - Martín-Bueno - Pina 2000, 88 además de Roddaz 1986, 333.

98 DurÁN 1952, después comentados en EsPINOSA 1984,141-142. 
sistente en cinco troqueles de acuñación y varias monedas acuñadas hacia el año 2 d.C. con las efigies de Cayo y Lucio César en el taller de Lugdunum (RIC 205-207). Este conjunto podría informar sobre la probable instalación de un taller itinerante de acuñación en Calagurris -tal vez auxiliar del de Lugdunum ${ }^{99}$ en ese periodo bien en relación con la necesidad de servir moneda al nada despreciable número de tropas acantonadas en las áreas más septentrionales del territorio peninsular entre los años 15 a.C. y 4 d.C., bien en directa vinculación con el viaje que Lucio César había previsto realizar a Hispania en ese mismo año y al que, necesariamente, hubieron de precederle algunos indeterminados preparativos.

La realidad descrita hasta aquí nos posiciona ante un interés de la administración augustea - estimulado sin duda con la presencia personal del Princeps ${ }^{-100}$ en la condición de eje de comunicaciones del Ebro Medio - como probaría, de hecho, la propia elección del emplazamiento de Caesar Augusta ${ }^{101}$ y, con ella, la integración de todo ese espacio central del valle en el conventus gestionado desde dicho centro, precisamente, a partir de este momento- ${ }^{102} \mathrm{y}$, con él, del solar vascón, focalizando, además, la atención en éste hacia el espacio meridional y ribereño del territorio y hacia el más septentrional y oriental del mismo, el primero en su condición de acceso a la Meseta y al área cántabra y del Noroeste y el segundo en su virtud de comunicación con Aquitania y con el Cantábrico. Ello no sería óbice, sin embargo, para que, como sucederá en otras regiones hispanas -en una tendencia que puede llevarse hasta la época julio-claudia- ${ }^{103}$ otros enclaves de la zona -marginales o no a los dos proyectos de reorganización territorial aquí descritos- fueran también sensibles a la influencia de la nueva época, ${ }^{104}$ un periodo, sin duda decisivo en la consolidación de la presencia romana, iniciada varias centurias antes, en los años de la conquista. De este modo -y aunque, en ocasiones, las bases estratigráficas con que contamos son endebles o los materiales no han sido adecuadamente publicados- sí puede trazarse un somero panorama -complemento del que ya anotamos en otra ocasión, con carácter más diacrónico- ${ }^{105}$ sobre las transformaciones atestiguadas por las comunidades urbanas del área en el periodo que nos ocupa.

99 García y Bellido - Blázquez 2001, 221.

100 Martín-Bueno 1993, 112.

101 BeLtrán LlORIS 2007, 6-9.

102 OzcáRIz 2006, 61. Si más arriba comentábamos el interés que, para Augusto, tuvo el conocimiento legado por la historiografía enciclopédica contemporánea respecto de los accidentes geográficos y rasgos étnicos del Norte peninsular, no debe olvidarse que sería en este momento cuando, también, se estableciesen los límites conventuales que separarían, al menos a efectos territoriales, a vascones y a várdulos, y, por tanto, el distrito de Caesar Augusta y el de Clunia (PerÉx - RodríGuez Morales 2011).

103 Como planteamiento general para el periodo julio-claudio en la zona debe verse GaLVE - Magallón - Navarro 2005, además de Beltrán Lloris - Martín-Bueno - Pina 2000, 135-136 y del ya clásico trabajo de Martín-Bueno 1999.

104 Con carácter general, y para el cambio de Era como primer momento de la urbanización de diversas civitates del ámbito vascón, en particular del correspondiente al territorio actualmente navarro, véase Mezquíriz 1997. Para la continuidad del poblamiento, prueba de que, en la mayor parte de los casos, Roma sencillamente mantuvo la organización territorial precedente a partir de un procedimiento de innovación jurídica y territorial, de potenciación, puede verse CASTIELLA 2004.

105 ANDReu 2004-2005, 292-297. 
Así, y comenzando por el territorio más meridional, a orillas del Ebro, nos consta que Calagurris comenzó a dotarse de una organización urbanística racionalizada a partir del momento de su promoción jurídica ${ }^{106}$ y que Gracchurris se remodela notablemente en el cambio de Era anulando una mal conocida organización urbana romano republicana de los tiempos de su fundación por Ti. Sempronio Graco ${ }^{107}$ siendo todavía muy insuficiente la información que tenemos, al menos para el núcleo urbano, respecto de Cascantum que, verosímilmente, para aquél momento ya contaba con una notable red de explotaciones agrícolas al modo de villae. ${ }^{108}$ En el área más septentrional, en su reborde occidental, y en relación con la apertura de la vía hacia Aquitania, nos consta que, como vimos, tanto la ciudad romana de Los Bañales de Uncastillo, como la del Cabezo Ladrero de Sofuentes o como la de Campo Real/Fillera de Sos, experimentaron un notable desarrollo y, probablemente, una evidente atracción demográfica. ${ }^{109}$ No lejos de allí, en relación con la citada arteria de comunicación, Cara debió de dotarse de un edificio público, acaso perteneciente, al foro, precisamente hacia el cambio de Era aunque objeto de remodelaciones en épocas posteriores. ${ }^{110}$ Por su parte, también los puntos de llegada de estas vías, como Oiasso -cuya primera instalación portuaria podría corresponder, precisamente, a los comienzos del siglo I a.C.- ${ }^{111}$ Iacca -donde, pese a la continuidad del poblamiento, ${ }^{112}$ algunos materiales parecen evidenciar ya una nítida presencia romana en el cambio de Era-;113 o Pompelo -que, para época de Augusto, parece ve construir algunas viviendas, un gran macellum al que más tarde se superpondrá la Catedral y, tal vez, la primitiva red de cloacas $-{ }^{114}$ dan muestras del feliz momento de urbanización que vive la zona y que, sin duda, afectaría también a otros enclaves relativamente separados de estos núcleos. Un ejemplo, en este sentido, podría ser el de Andelo que, parece, es una floreciente ciudad ya en el siglo I a.C. a juzgar por la cerámica atestiguada en sus niveles más antiguos ${ }^{115}$ o por el conocido mosaico de Likine, ${ }^{116}$ por más que su despegue monumental y jurídico no se producirá hasta la época flavia. ${ }^{117}$ Esta comunidad puede verse casi como un paradigma de lo que sucederá en la mayor parte de las ciudades del territorio vascón durante la era de Augusto, todas -herederas de importantes oppida de la Edad del Hierro II- acabarán por experimentar un muy notable desarrollo en fun-

106 Espinosa 1984, además de IGUÁCel 2002, 47.

107 HernáNDEZ Vera - CASAdo 2002, 180.

108 Gómara 2009.

109 Véase, al respecto, con bibliografía, ANDREu 2011, 34-38.

110 Mezquíriz 1975, 84-85.

111 Gereñu, López Colom - Urteaga 1997, 473. Contra esta posibilidad y atendiendo, más bien, a un interés flavio - que, efectivamente, potenciaría la actividad del puerto de Oiasso- debe verse FernándeZ OCHOA - MORILLO 1994, 151.

112 JUSTE 1992.

113 ONA ET ALII 1987, 11.

114 Mezquíriz 1976, 191, además de, para la red de saneamiento, Mezquíriz 1965, 379 y, con carácter general, subrayando los primeros años del siglo I d.C. como los de inicio del urbanismo pompelonense, MeZquíriz 1958, 218 y 1978, 18.

115 Mezquíriz 1987, 518.

116 MezQuíriz 1991-1992, 366.

117 Velaza 1998, 630. Sobre la promoción de este enclave, y las implicaciones que tuvo para su elite local, puede verse la reciente aportación de GARCía FerNáNDEZ 2012. 
ción de su conversión en civitates cabeceras de un territorio que interesaba controlar pero, sin embargo -salvo las excepciones ya comentadas en el área más meridional del territorio- su definitiva integración jurídica no se operará hasta, precisamente, uno de los grandes momentos de restauración política augustea de cuantos conocerá la Historia de Roma, la época flavia. Ese desarrollo estatutario, sin embargo, habría sido imposible sin las bases políticas y territoriales establecidas por Augusto cuyo novus status fue, sencillamente, más allá de lo estrictamente político e institucional.

\section{Addendum}

Entregado este trabajo a imprenta, los notables hallazgos epigráficos y escultóricos producidos entre 2013 y 2015 en la ciudad romana de Los Bañales (Uncastillo, Zaragoza) han aportado algunos nuevos datos respecto de la vida urbana en el solar objeto de atención de estas reflexiones. Para una actualización, en ese sentido, debe verse ANDREU, Romero y MONTOYA 2014-2015.

\section{BibLiOgRAFÍA}

ABASCAL, J. M.

(2006): "Los tres viajes de Augusto a Hispania y su relación con la promoción jurídica de ciudades", Iberia 9, 63-78.

(1996): "Programas epigráficos augústeos en Hispania", Anales de Arqueología Cordobesa 7, 45-82.

Aguarod, Ma C. - Lostal, J. (1982): "La vía romana de las Cinco Villas", Caesaraugusta $55-56,167-218$.

AMELA, L.

(2000-2001): “La vía Tarraco-Oiasso (Str. 3, 4, 10)”, Pyrenae 31-32, 201-208.

(2012-2013): “La primera emisión latina de Turiaso", Turiaso 21, 93-101.

ANDREU, J.

(2004-2005): “Algunas consideraciones sobre las ciudades romanas del territorio vascón y su proceso de monumentalización”, Espacio, Tiempo y Forma. Serie 2. Historia Antigua 17-18, 251-300.

(2006): "Ciudad y territorio en el solar de los Vascones en época romana", [en] J. Andreu (ed.), Navarra en la Antigüedad. Propuesta de Actualización, Pamplona, 179-228.

(2009): "Sobre las élites municipales Calagurritanas: a propósito de los Granii de los rótulos monetales", Kalakorikos 14, 105-126.

(2011): "La ciudad romana de Los Bañales (Uncastillo, Zaragoza) en las fuentes históricas", [en] J. Andreu (ed.), La ciudad romana de Los Bañales (Uncastillo, Zaragoza): entre la historia, la arqueología y la historiografia, Zaragoza, 19-100 (=Caesaraugusta 82).

(2013): "Los Vascones van al Instituto: la imagen de la Navarra Antigua y de los Vascones en las publicaciones didácticas y escolares contemporáneas", [en] J. Andreu (ed.), Entre Vascones y Romanos: sobre las tierras de Navarra en la Antigüedad, Pamplona, 355-383 (=Cuadernos de Arqueología de la Universidad de Navarra 21). 
Andreu, J. (ed.)

(2006): Navarra en la Antigüedad. Propuesta de Actualización, Pamplona.

(2009): Los Vascones de las fuentes antiguas. En torno a una etnia de la Antigüedad Peninsular, Barcelona.

(2013): Entre Vascones y Romanos: sobre las tierras de Navarra en la Antigüedad, Pamplona (=Cuadernos de Arqueología de la Universidad de Navarra 21).

Andreu, J. - Bienes, J. J. - Lasaosa, E. - Romero, L. (2014): "El foro de la ciudad romana de Los Bañales (Uncastillo, Zaragoza): aspectos estructurales y cronológicos preliminares", [en] XVIII Congreso de la Asociación Internacional de Arqueología Clásica (Mérida, 2012), MNAR/ICAC, Mérida, s. pp.

ANDREu, J. - JoRDÁN, Á. A. (2007): "Nuevas reflexiones en torno a las fuentes literarias sobre los Vascones en la Antigüedad", Lucentum 26, 233-252.

ANDreu, J. - JordÁn, Á. A. - ARMEndÁRIz, J. (2010): "Nuevas aportaciones a la Epigrafía de Campo Real/Fillera (Sos del Rey Católico/Sangüesa)", Zephyrus 65, 179-198.

Andreu, J. - Romero, L., - Montoya, R. (2014-2015): “Los Bañales (Uncastillo, Zaragoza), ciuitas augústea", Anales de Arqueología Cordobesa 25-26, 49-70.

Antequera, F. - Padrós, P. - Rigo, P. - VÁzquez, D. (2010): “El suburbium occidental de Baetulo", [en] D. VAQUERIzo (ed.), Las áreas suburbanas en la ciudad histórica. Topografia, usos, función, (=Monografías de Arqueología Cordobesa 18), Córdoba, 173-210.

Ariño, E. - Lanzarote, P. - Magallón, Ma Á. - Martín-Bueno, M. (1997): "Las vías de Italia in Hispania y ab Asturica Terracone", [en] Voies Romaines du Rhône à l'Ebre: via Domitia et via Augusta, Paris, 246-257.

ArmendÁRIZ, J. (2008): De aldeas a ciudades. El poblamiento en Navarra durante el primer milenio a.C., Pamplona.

Aujac, G. (1966): Strabon et la science de son temps. Les sciences du monde, Paris.

BELTRÁn Lloris, F.

(1992): "Caesar Augusta, ciudad de Augusto", Caesaraugusta 69, 31-44.

(2006): "El valle Medio del Ebro durante el periodo republicano: de limes a conventus", [en] G. Cruz Andreotti - P. Le Roux - P. Moret (eds.), La invención de una geografía de la Península Ibérica. II. La época imperial, Málaga, 217-240.

(2007-2008): "Marcas legionarias de la VI Victrix y la X Gemina en el foro de Caesar Augusta", Veleia 24-25, 1069-1079.

Beltrán Lloris, F. (coord.) (2007), Las capitales provinciales de Hispania. 4. Zaragoza. Colonia Caesar Augusta, Roma.

Beltrán Lloris, F. - Martín-Bueno, M. - Pina, F. (2000): Roma en la Cuenca Media del Ebro. La romanización en Aragón, Zaragoza.

Beltrán Lloris, F. - PinA, F. (1994): "Roma y los Pirineos: la formación de una frontera", Chiron 24, 104-133.

BELTRÁN LloRis, M.

(1992): "Lápida honorífica”, Arqueología 92, 95-96.

(2002): “Augusto y Turiaso", [en] Las aguas sagradas del municipium Turiaso Zaragoza, 259-296 (=Caesaraugusta 76).

Bendala, M. (1990): "El plan urbanístico de Augusto en Hispania: precedentes y pautas macroterritoriales", [en] Stadtbild und Ideologie: die Monumentalisierung hispanischer Städte zwischen Republik und Kaiserzeit (Oktober, 1987), München, 25-43. 
Blázquez Martínez, J. Ma (2007-2008): "Los Vascones en las fuentes literarias de la Antigüedad y en la historiografía actual", Trabajos de Arqueología Navarra 20, 103-150.

Bost, J.-P. (2009): “Les échanges interrégionaux dans l'Ouest Pyrénéen à l'époque romaine (Ier siècle avanti J. C.-Ve siècle après J. C.)", [en] J. Santos Yanguas (ed.), Los tiempos antiguos en los territorios pirenaicos, Vitoria, 107-135.

BracCesi, L. (1982): "Plinio storico", [en] Plinio il Vecchio sotto il profilo storico e letterario, Como, 53-82.

CANTón, E. (2005): “Sobre la expansión vascona en las fuentes literarias”, Veleia 22, 129-144.

Castiella, A.

(2003): Por los caminos romanos de Navarra, Pamplona.

(2004): "Peculiaridades del poblamiento prerromano en territorio vascón: Navarra", Cuadernos de Arqueología de la Universidad de Navarra 12, 177-233.

CAstillo, C. (1981): "Un nuevo documento de la legio IV Macedonica en Hispania", [en] Primera Reunión Gallega de Estudios Clásicos (Julio, 1979), Santiago de Compostela, 134-140.

Castillo Pascual, P. (2002): "Las fuentes clásicas", [en] Así era la vida en una ciudad romana: Calagurris Iulia, Calahorra, 7-15.

Cauvet, B. - Domergue, C. - Urteaga, M. (2005) : "Mines et métallurgies en Aquitaine et en Hispanie septentrionale sous les Julio-Claudiens", [en] L'Aquitaine et l'Hispanie septentrionale à l'époque julio-claudienne. Organisation et exploitation des espaces provinciaux, Bordeaux, 423-460.

Churruca, J. DE (2009): “Los territorios pirenaico-occidentales en la obra de Estrabón”, [en] J. Santos Yanguas (ed.), Los tiempos antiguos en los territorios pirenaicos, Vitoria, 37-54.

Cortio, M M L. (2006): "El papel del conventus iuridicus en la descripción geográfica de Plinio el Viejo. El caso bético", [en] G. Cruz Andreotti - P. Le Roux - P. Moret (eds.), La invención de una geografía de la Península Ibérica. II. La época imperial, Málaga, 271-304.

Dueck, D. (2010): Strabo of Amasia. A Greek man of letters in Augustan Rome, London-New York.

Dupré, N. (1973): “Le place du vallée de l'Ebre dans l'Espagne Romaine: recherches de géographie historique", Mélanges Casa de Velázquez 9, 134-175.

Durán, R. (1952): "Breves consideraciones sobre los troqueles romanos del Museo Valencia de D. Juan", Numisma 2/2, 111-116.

ESPINOSA, D.

(2013a): "La Historia Natural de Plinio el Viejo: un proyecto "augusteo" de época Flavia", [en] R. M ${ }^{a}$ Cid - E. García Fernández (eds.), Debita verba I. Estudios en Homenaje al Profesor Julio Mangas Manjarrés, Oviedo, 671-684.

(2013b): Plinio y los oppida de antiguo Lacio. El proceso de difusión del Latium en la Hispania Citerior, Tesis doctoral inédita, Madrid.

Espinosa, U. (1984): Calagurris Iulia, Calahorra.

Fernández OCHOA, C. - Morillo, Á. (1994): De Brigantium a Oiasso. Una aproximación al estudio de los enclaves marítimos cantábricos en época romana, Madrid.

Galve, Ma P. - Magallón, Ma Á. - Navarro, M. (2005): "Las ciudades romanas del valle Medio del Ebro en época julio-claudia", [en] L'Aquitaine et l'Hispanie septentrionale à l'époque julio-claudienne. Organisation et exploitation des espaces provinciaux, Bordeaux, 170-214. 
García Alonso, J. L. (2003): La Península Ibérica en la Geografía de Claudio Ptolomeo, Universidad del País Vasco, Vitoria.

GARCÍA FERNÁNDEZ, E.

(2009): "Gracchurris y los oppida de antiguo Lacio", [en] J. Andreu (ed.), Los Vascones de las fuentes antiguas. En torno a una etnia de la Antigüedad Peninsular, (=Instrumenta 32), Barcelona, 215-230.

(2012): "Sobre la condición latina y su onomástica: los ediles de Andelo", Espacio, Tiempo y Forma. Serie 2. Historia Antigua 25, 423-436.

García y Bellido, Ma P., - BlázQuez, C. (2001): Diccionario de cecas y pueblos hispánicos con una introducción a la numismática antigua de la Península Ibérica. II. Catálogo de cecas y pueblos, Madrid.

Gereñu, M. - López Colom, Ma M. - Urteaga, M. (1997): "Novedades de Arqueología Romana en Irún-Oiasso. 1992-96", Isturitz 8, 467-489.

Gómara, M. (2009): "El municipium Cascantum en la Antigüedad: valoración general y aspectos arqueológicos", [en] J. Andreu (ed.), Los Vascones de las fuentes antiguas. En torno a una etnia de la Antigüedad Peninsular, (=Instrumenta 32), Barcelona, 403-414.

Gómez-PANTOJA, J.

(2000a): "Legio IIII Macedonica", en Les Légions de Rome sous le Haut-Empire. Tome I, Paris, 105-117.

(2000b): "Legio X Gemina”, [en] Les Légions de Rome sous le Haut-Empire. Tome I, Paris, 169-190.

Gorrochategui, J. (2009): "Vasco antiguo: algunas cuestiones de geografía e historia lingüísticas”, Palaeohispanica 9, 539-555.

GurT, J. M. - RodÀ, I. (2005): "El Pont del Diable. El monumento romano dentro de la política territorial augústea", Archivo Español de Arqueología 78, 147-165.

Hernández Vera, J. A. - CASAdo, P. (2002): "La fundación de Graccurris", [en] J. L. Jiménez y A. Ribera (coords.), Valencia y las primeras ciudades romanas de Hispania, Valencia, 173-182.

Hernández Vera, J. A. - Martínez Torrecilla, J. M. - NúÑez, J. (1999): “La presa y el ninfeo de El Sotillo (Alfaro, La Rioja)", Zephyrus 52, 239-260.

IguÁcel, P. (2002): “El trazado urbano”, [en] Así era la vida en una ciudad romana: Calagurris Iulia, Calahorra, 39-50.

JorDÁn, Á. A.

(2006): "Un homenaje a Marco Aurelio y Lucio Vero procedente de Calahorra", [en] E. Melchor - J. F. Rodríguez Neila (eds.), Poder central y autonomía municipal: la proyección pública de las elites romanas de Occidente, Córdoba, 113-130.

(2011): "Inscripciones, monumentos anepígrafos, dudosos, sellos y grafitos procedentes del municipium ignotum de Los Bañales de Uncastillo", [en] J. Andreu (ed.), La ciudad romana de Los Bañales (Uncastillo, Zaragoza): entre la historia, la arqueología y la historiografia, (=Caesaraugusta 82), Zaragoza, 289-337.

Juste, N. N. (1992): "Excavaciones en el solar de la C/7 de Febrero de 1893 - esquina con la C/Cantores, de Jaca", [en] Arqueología Aragonesa 1990, Zaragoza, 271-274.

LAMBÁN, J. (1982): "Hallazgo arqueológico", Suessetania 1, 18.

LAPORTe, J. P. (1996): “Notes sur l'aqueduc de Saldae (Bougie)”, L'Africa Romana 11, 711762. 
LARRAÑAGA, K.

(2007): El hecho colonial romano en el área circumpirenaica Occidental, Vitoria. (2009): "Marginalidad e inserción en los circuitos de mercado imperiales: el caso del Pirineo Occidental", [en] J. Santos Yanguas (ed.), Los tiempos antiguos en los territorios pirenaicos, Vitoria, 83-104.

LASAOSA, E. (2013): "Vajilla de mesa (terra sigillata y cerámica engobada) de la ciudad romana de Los Bañales (Uncastillo, Zaragoza)", Espacio, Tiempo y Forma. Serie 2. Historia Antigua 26, 303-338.

Lostal, J. (1992): Los miliarios de la provincia Tarraconense (conventos Tarraconense, CAesaraugustano, Cluniense y Cartaginense), Zaragoza.

Magallón, Má. Á.

(1987): La red viaria romana en Aragón, Zaragoza.

(1990): "Vías de comunicación y poblamiento romano en la Comarca de las Cinco Villas", [en] V Jornadas de Estudios sobre las Cinco Villas. Los caminos en la Historia de las Cinco Villas, Ejea de los Caballeros, 23-42.

Martín-Bueno, M.

(1993): "La ciudad hispanorromana en el valle del Ebro", [en] La ciudad hispanorromana, Barcelona, 108-127.

(1999): “La ciudad julio-claudia, ¿una estrella fugaz?”, [en] II Congreso de Arqueología Peninsular (Zamora, 1996), Zamora, 117-122.

MEZQuíriz, Má.

(1958): La excavación estratigráfica de Pompaelo. I. Campaña de 1956, Pamplona.

(1965): "Segunda campaña de excavaciones en el área urbana de Pompaelo", Príncipe de Viana 100-101, 379-384.

(1975): "Primera campaña de excavaciones en Santacara (Navarra)", Príncipe de Viana 138-139, 83-109.

(1976): “Algunas aportaciones al urbanismo de Pompaelo", [en] Symposion de ciudades augusteas. I, Zaragoza, 189-194.

(1977): "Cerámica prerromana hallada en las excavaciones de Santacara (Navarra)", [en] XIV Congreso Nacional de Arqueología (Vitoria 1975), Vitoria, 519-610.

(1978): Pompaelo II, Pamplona.

(1987): "La ciudad de Andelos: secuencia estratigráfica y evolución cronológica", [en] Primer Congreso General de Historia de Navarra. 1. Comunicaciones, Pamplona, 517-530. (1991-1992): "Pavimento de opus signinum con inscripción ibérica en Andelos", Trabajos de Arqueología Navarra 10, 365-367.

(1995-1996): "La producción de vino en época romana a través de los hallazgos en territorio navarro", Trabajos de Arqueología Navarra 12, 63-89.

(1997): "Claves del urbanismo romano en el territorio de Navarra", Complutum 6/1, 441450.

(2006): "La antigua ciudad de los Carenses", Trabajos de Arqueología Navarra 19, 147268.

(2009): Andelo, ciudad romana, Pamplona.

Moreno, I.

(2001): Descripción de la vía romana de Italia a Hispania en las provincias de Burgos y Palencia, Palencia.

(2009): Item a Caesarea Augusta Beneharnum. La carretera romana de Zaragoza al Bearn, Ejea de los Caballeros. 
NaAs, V. (2002): Le projet encyclopédique de Pline l'Ancien, Roma.

Navarro, J. (2010): "Navarra en la Antigüedad tardía (siglos III-VII)", [en] J. Navarro (ed.), Nueva Historia de Navarra, Pamplona, 89-117.

Nicolet, C. (1988): L'inventaire du monde. Géographie et politique aux origines de l'Empire romain, Paris.

Ona, J. L. - Paz, J. Á. - Pérez Casas, J. A. - De Sus, Ma L. (1987): Arqueología urbana en Jaca: el solar de las Escuelas Pías, Zaragoza.

Ortiz, E. - PAz, J. Á. (2011): "El vidrio romano en Los Bañales (Uncastillo, Zaragoza): revisión preliminar", [en] J. Andreu (ed.), La ciudad romana de Los Bañales (Uncastillo, Zaragoza): entre la historia, la arqueología y la historiografia, Zaragoza, 355-388 (=Caesaraugusta 82).

OzCÁRIz, P. (2006): Los conventus de la Hispania Citerior, Madrid.

Palao, J. J. (2013): "El ejército romano y la ordenación del territorio en Hispania: factores estratégicos, logísticos, geográficos y control territorial durante el Alto Imperio”, [en] J. Santos Yanguas - G. Cruz Andreotti (eds.), Romanización, fronteras y etnias en la Roma antigua: el caso hispano, Vitoria, 83-112.

PeÑA, Y. (2010): Torcularia. La producción de vino y aceite en Hispania, Tarragona.

PERÉX, M $\mathrm{M}^{\mathrm{a}}$.

(1984): Los Vascones (el poblamiento en época romana), Pamplona.

(1988): “Tarraca, ciudad federada del convento jurídico cesaraugustano", [en] M. Mayer - J. M Nolla - J. Pradó (eds.), De les structures indígenes a la organització provincial romana de la Hispània Citerior: homenatge a Josep Estrada i Garriga, Barcelona, 485-488.

Peréx, Ma J. - Rodríguez Morales, J. (2011): "Término augustal hallado en Lekunberri (Navarra): estudio preliminar", Trabajos de Arqueología Navarra 23, 5-20.

PerÉx, Ma J. - UnzU, M. (1997-1998): "Necrópolis y poblado de época romana en Espinal (Navarra)", Trabajos de Arqueología Navarra 13, 75-155.

RAmírez SÁDABA, J. L. (2006): "Las ciudades vasconas según las fuentes literarias y su evolución en la tardoantigüedad", Antigüedad y Cristianismo 23, 185-202.

RodDaz, J. M. (1986): Guerras civiles et romanisation dans la valle de 1'Ebre", Revue des Études Anciennes 88, 317-338.

Rodríguez Colmenero, A. (1979): Augusto e Hispania. Conquista y organización del Norte Peninsular, Bilbao.

Roldán, J. M. - WulfF, F. (1001): Citerior y Ulterior. Las provincias romanas de Hispania en la era republicana, Madrid.

Roller, M. B. (2009): "The politics of aristocratic competition: innovation in Livy and Augustan Rome", [en] W. J. Dominik - J. Garthwaite - P. A. Roche (eds.), Writing Politics in Imperial Rome, Leiden-Boston, 153-172.

Salinas, M. - Palao, J. J. (2012): "Nuevo miliario de Augusto procedente de Fuenteguinaldo (Salamanca)", Archivo Español de Arqueología 85, 273-279.

SANTOS Yanguas, J. (2007-2008): “¿Todavía saltus frente a ager en territorio vascón?”, Arkeolan 15, 165-171.

SAntos Yanguas, J - CRUz Andreotti, G. (eds.) (2013): Romanización, fronteras y etnias en la Roma antigua: el caso hispano, Vitoria. 
SAYAS, J. J.

(2000): "Unidad en la diversidad: la visión de Estrabón de algunos pueblos peninsulares", [en] G. Cruz Andreotti (ed.), Estrabón e Iberia: nuevas perspectivas de estudio, Málaga, 153-208.

(2010): "Vascones y romanización de Navarra", [en] J. Navarro (ed.), Nueva Historia de Navarra, Pamplona, 41-87.

SAYAs, J. J. - PerÉX, Ma J. (1987): "La red viaria en época romana en Navarra", [en] Primer Congreso General de Historia de Navarra. 2. Comunicaciones, Pamplona, 581-608.

SCHENCK, J. L. (1995): "Métamorphisme et métamorphoses. Essai d'identification d'un atelier de taille: les marmorarii de Saint-Béat", [en] Les marbres blancs des Pyrénées. Approches scientifiques et historiques, Bordeaux, 169-196.

Torregaray, E. (2013): "Vascones y Vacceos: una historia de confusión”, [en] J. Santos Yanguas - G. Cruz Andreotti (eds.), Romanización, fronteras y etnias en la Roma antigua: el caso hispano, Vitoria, 459-475.

Uribe, P. - Magallón, Ma Á. - Fanlo, J. - Martínez, M. - Domingo, R. - Reklaitjte, I. PÉREz LAMBÁN, F. (2011): "La presa romana de Muel: novedades de hidráulica romana en el valle del Ebro", [en] L. Lagóstena - J. L. Cañizar - L. Pons (eds.), Aquam perducendam curavit. Captación, uso y administración del agua en las ciudades de la Bética y el Occidente Romano, Cádiz, 333-345.

Urteaga, M. (2007-2008): “El Vasconum saltus y Oiasso”, Arkeolan 15, 171-184.

VelazA, J. (1998): "La evolución de la ciudad romana de Andelo a la luz de los testimonios epigráficos", [en] Los orígenes de la ciudad en el Noroeste hispánico (Lugo, 1996), Lugo, 623-642.

Walsh, P. G. (1970): Livy. His historical aims and methods, Cambridge.

ZuZA, C. (2013): "El 'patio oriental' de la villa romana de Liédena (Navarra) en el Bajo Imperio y la annona militaris: una propuesta", [en] J. Andreu (ed.), Entre Vascones y Romanos: sobre las tierras de Navarra en la Antigüedad, Pamplona, 291-308 (=Cuadernos de Arqueología de la Universidad de Navarra 21). 